\title{
Analisis Pengaruh Supervisi Pengawas Dan Supervisi Kepala Sekolah Terhadap Kinerja Guru Di Madrasah Ibtidaiyah Kecamatan Sukau Lampung Barat
}

\author{
Hazli $^{1}$, Rendy Rinaldy Saputra ${ }^{2}$ \\ ${ }^{1}$ Pengawas Madrasah Kementrian Agama Lampung Barat \\ ${ }^{2}$ Sekolah Tinggi Ilmu Tarbiyah (STIT) Al Multazam, Lampung Barat \\ ${ }^{1}$ kemenaghazli@gmail.com \\ ${ }^{2}$ rendyrinaldy96@gmail.com
}

\begin{abstract}
ABSTRAK
Penelitian ini dilatarbelakangi oleh standar mutu pengawas nasional yang menyatakan bahwa pengawas sekolah memiliki peran sebagai supervisor manajerial serta supervisor akademik yang dirasa akan berjalan baik apabila terdapat dukungan dari kepala sekolah. Penelitian ini bertujuan untuk mengevaluasi rangkaian kegiatan supervisi yang dilakukan dengan cara menganalisis sejauh mana pengaruh supervisi yang dilakukan oleh pengawas sekolah dan kepala sekolah terhadap kinerja guru di Madrasah Ibtidaiyah Kecamatan Sukau Lampung Barat. Penelitian ini menggunakan pendekatan kuantitatif dengan metode analisis regresional untuk melihat sejauh mana suatu variabel mempengaruhi variabel lainnya. Hipotesis yang dibangun dalam penelitian ini 1) supervisi pengawas berpengaruh positif dan signifikan terhadap kinerja guru, 2) supervisi kepala sekolah berpengaruh positif dan signifikan terhadap kinerja guru, dan 3) supervisi pengawas dan kepala sekolah secara bersama-sama berpengaruh positif dan signifikan terhadap kinerja guru. Analisis dilakukan menyebarkan kuisioner terhadap 43 orang responden dan diolah dengan pendekatan kuantutatif dengan hasil bahwa 1) supervisi pengawas berpengaruh positif dan signifikan terhadap kinerja guru, 2) supervisi kepala sekolah tidak berpengaruh positif dan signifikan terhadap kinerja guru, dan 3) supervisi pengawas dan kepala sekolah secara bersama - sama berpengaruh positif dan signifikan terhadap kinerja guru.
\end{abstract}

Kata Kunci : Supervisi, Kinerja Guru

\section{PENDAHULUAN}

Salah satu peran pengawas sekolah yang tercantum dalam standar mutu pengawas nasional yang telah ditetapkan oleh Direktorat Jenderal Peningkatan Mutu Pendidikan dan Tenaga Kependidikan Direktorat Tenaga Kependidikan Departemen Pendidikan Nasional adalah sebagai supervisor akademik (sudjana, 2006). Sebagai supervisor akademik, pengawas sekolah dituntut untuk mampu memberikan pembinaan, pendampingan serta pengawasan dalam rangka meningkatkan profesionalisme guru sehingga mampu meningkatkan mutu proses pembelajaran. Hal ini dilakukan guna meningkatkan kualitas suatu sekolah secara keseluruhan melalui pengingkatan kinerja guru dengan bantuan pengawa sekolah selaku supervisor akademik.

Supervisi secara sederhana dapat diartikan sebagai suatu rangakaian kegiatan pengawasan yang dilakukan oleh atasan kepada bawahan. Kegiatan supervisi merupakan salah satu rangkaian kegiatan manajerial yang ada pada fungsi pengawasan guna menilai dan menjaga kinerja karyawan untuk berfokus pada tujuan yang ingin dicapai. Dalam dunia pendidikan, salah satu fungsi supervisi adalah guna meningkatkan kualitas kinerja guru. Pada lingkup sekolah, kepala sekolah selaku pimpinan tertinggi memiliki tugas selaku supervisor yang bertugas untuk membina serta membantu guru dalam meningkatkan kemampuan profesionalnya. Karenanya, dalam melaksanakan peranan sebagai supervisor akademik seorang pengawas tidak akan terlepas dari kepala sekolah sebagai mitra kerjanya. Kegiatan supervisi yang dilakukan oleh pengawas secara terus menerus tidak akan mencapai hasil yang maksimal tanpa adanya dukungan dari seluruh pihak terutama kepala sekolah selaku pimpinan.

Dalam beberapa penelitian dinyatakan bahwa supervisi merupakan upaya yang dapat dilakukan dalam rangka meningkatkan kualitas kinerja guru. Hal ini dinyatakan oleh Mustofa, dkk (2017) yang menyebutkan bahwa Terdapat pengaruh yang signifikan supervisi pengawas satuan pendidikan terhadap kinerja 
guru pada SMA Ma'arif NU 5 Purbolinggo, Kabupaten Lampung Timur. Penelitian lain yang dilakukan oleh Sumarni, Dkk (2017) menyebutkan bahwa Supervisi Akademik pengawas sekolah berpengaruh positif dan signifikan secara parsial terhadap Kinerja Guru di SMK Negeri Se - kecamatan Tamalate Kota Makassar. Dengan demikian, dapat disimpulkan bahwa semakin rutin dan obyektifnya pelaksanaan supervisi akademik pengawas sekolah, maka akan meningkatkan Kinerja Guru. Supriono (2014) menyimpulkan bahwa pelaksanaan supervisi kepala sekolah memberikan sumbangan efektif sebesar 79\% terhadap kinerja guru. Lebih lanjut, Brotosedjati, (2012) menyebutkan bahwa supervisi kunjungan kelas oleh kepala sekolah berpengaruh positif dan signifikan terhadap kinerja guru, besarnya pengaruh supervisi kunjungan kelas oleh kepala sekolah mencapai $85,4 \%$

Berdasarkan hasil yang telah dijelaskan oleh peneliti terdahulu, secara umum dapat disimpulkan bahwa supervisi pengawas serta supervisi kepala sekolah masing - masing berpengaruh terhadap peningkatakn kinerja guru. Akan tetapi dirasa masih perlu dilakukan penelitian yang menganalisis kedua faktor tesebut secara bersamaan guna melihat pengaruh kedua kegiatan supervisi yang dilakukan baik oleh pengawas maupun kepala sekolah secara simultan terhadap peningkatan kinerja guru. Karenanya penulis tertarik untuk melakukan penelitian yang mengkaji sejauh mana pengaruh supervisi pengawas serta supervisi kepala sekolah dalam meningkatkan kinerja guru di Madrasah Ibtidaiyah Kecamatan Sukau Lampung Barat. Untuk itu penelitian ini bertujuan untuk mengetahui apakah terpadat pengaruh antara : 1) supervisi pengawas terhadap kinerja guru di Madrasah Ibtidaiyah Kecamatan Sukau Lampung Barat, 2) supervisi kepala sekolah terhadap kinerja guru di Madrasah Ibtidaiyah Kecamatan Sukau Lampung Barat, dan 3) pengaruh supervisi pengawas dan kepala sekolah secara simultan terhadap kinerja guru di Madrasah Ibtidaiyah Kecamatan Sukau Lampung Barat

\section{METODE PENELITIAN}

Metode yang digunakan dalam penelitian ini adalah metode kuantitatif dengan pendekatan regresional guna melihat apakah terdapat pengaruh antara satu atau lebih variabel terhadapa variabel lainnya. Hal ini seperti yang disebutkan oleh Priyatno, (2008). Analisis regresi linier berganda yaitu analisis yang bertujuan untuk mengetahui ada tidaknya hubungan ketergantungan, dan arah hubungan ketergantungan antara dua atau lebih variabel bebas atau independen $(\mathrm{X})$ dengan variabel terikat atau dependen $(\mathrm{Y})$ apakah positif atau negatif Variabel yang digunakan dalam penelitian ini adalah variabel kinerja guru $(\mathrm{Y})$ sebagai variabel terikat, serta variabel supervisi pengawas (X1) dan variabel supervisi kepala sekolah (X) sebagai variabel bebas.

Guna memperoleh data yang dibutuhkan dalam proses analisis, dilakukan pengumpulan data dengan menggunakan angket kuisioner berskala Likert yang disebarkan ke tiga (3) madrasah ibtidaiyah yang ada dikecamatan Sukau Lampung Barat dengan subjek penelitian berjumlah 43 orang guru. Pengambilan sampel penelitian dilakukan berdasarkan pendapat Arikunto (1989) yang menyatakan bahwa untuk sekedar ancer-ancer maka apabila subyeknya kurang dari 100 lebih baik diambil semua, dan jika jumlah populasinya besar dapat diambil antara 10$15 \%$ atau $20-25 \%$ atau lebih. Dengan demikian, dikarenakan jumlah populasi dalam objek penelitan adalah dibawah 100 (43) guru, maka penulis menggunakan sampel total dalam penelitian (penelitian populasi) Data yang terkumpul kemudian dianalisis guna memastikan bahwa instrument yang digunakan dalam pengambilan data memenuhi syarat untuk dilakukan penarikan kesimpulan dengan melakukan uji hipotesis.

Hipotesis yang dibangun dalam penelitian ini adalah :

1. Supervisi pengawas berpengaruh positif dan signifikan terhadap kinerja guru

2. Supervisi kepala sekolah berpengaruh positif dan signifikan terhadap kinerja guru

3. Supervisi pengawas dan kepala sekolah secara simultan berpengaruh positif dan signifikan terhadap kinerja guru

Hipotesis penelitian yang dibangun akan diuji dengan menggunakan persamaan regresi linear berganda dengan kriteria pengujian terima $\mathrm{H} 0$ jika nilai $\mathrm{T}$ hitung lebih besar dari nilai $\mathrm{T}$ tabel atau nilai Signifikansi lebih besar dari $0,05 \%$.

\section{HASIL \& PEMBAHASAN}

\section{a. Uji Validitas}

Penelitian dilakukan dengan melakukan analisis data yang diperoleh melalui penyebaran angket kuisisoner berskala Likert 
yang di sebarkan ke seluruh responden dalam penelitian. Sebelum kuisioner digunakan untuk penelitian lebih lanjut, terlebih dahulu dilakukan uji validitas serta uji reliabilitas guna melihat sejauh mana kuisioner yang telah disusun dapat digunakan dalam penelitian. Adapun masing masing hasil uji instrument disajikan dalam tabel berikut :

Tabel 1. Uji Validitas Instrument Supervisi Pengawas

\begin{tabular}{cccc}
\hline Item & $\mathbf{r}$ hitung & $\begin{array}{c}\mathbf{r} \text { tabel pada taraf } \\
\text { signifikan } \mathbf{5 \%}\end{array}$ & Keterangan \\
\hline Item 1 & 0.403 & 0,374 & Valid \\
Item 2 & 0.575 & 0,374 & Valid \\
Item 3 & 0.479 & 0,374 & Valid \\
Item 4 & 0.464 & 0,374 & Valid \\
Item 5 & 0.506 & 0,374 & Valid \\
Item 6 & 0.437 & 0,374 & Valid \\
Item 7 & 0.511 & 0,374 & Valid \\
Item 8 & 0.458 & 0,374 & Valid \\
Item 9 & 0.503 & 0,374 & Valid \\
Item 10 & 0.426 & 0,374 & Valid \\
\hline
\end{tabular}

Sumber : Data Primer Diolah

Tabel 2. Uji Validitas Instrument Supervisi Kepala Sekolah

\begin{tabular}{cccc}
\hline Item & $\mathbf{r}_{\text {hitung }}$ & $\begin{array}{c}\mathbf{r} \text { tabel pada taraf } \\
\text { signifikan 5\% }\end{array}$ & Keterangan \\
\hline Item 1 & 0.450 & 0,374 & Valid \\
Item 2 & 0.425 & 0,374 & Valid \\
Item 3 & 0.400 & 0,374 & Valid \\
Item 4 & 0.399 & 0,374 & Valid \\
Item 5 & 0.428 & 0,374 & Valid \\
Item 6 & 0.430 & 0,374 & Valid \\
Item 7 & 0.442 & 0,374 & Valid \\
Item 8 & 0.549 & 0,374 & Valid \\
Item 9 & 0.481 & 0,374 & Valid \\
Item 10 & 0.464 & 0,374 & Valid \\
\hline
\end{tabular}

Sumber : Data Primer Diolah

Tabel 3. Uji Validitas Instrument Kinerja

\begin{tabular}{cccc}
\hline Item & r hitung & $\begin{array}{c}\mathbf{r} \text { tabel pada taraf } \\
\text { signifikan 5\% }\end{array}$ & Keterangan \\
\hline Item 1 & 0.390 & 0,374 & Valid \\
Item 2 & 0.405 & 0,374 & Valid \\
Item 3 & 0.468 & 0,374 & Valid \\
Item 4 & 0.430 & 0,374 & Valid \\
Item 5 & 0.423 & 0,374 & Valid \\
Item 6 & 0.526 & 0,374 & Valid \\
Item 7 & 0.444 & 0,374 & Valid \\
Item 8 & 0.518 & 0,374 & Valid \\
Item 9 & 0.407 & 0,374 & Valid \\
Item 10 & 0.472 & 0,374 & Valid \\
\hline
\end{tabular}

Sumber : Data Primer Diolah

Hasil analisis data yang ditampilkan dalam tabel $1-3$ merupakan hasil analisis uji validitas yang dilakukan terhadap masing masing instrument yang akan digunakan dalam penelitian. Berdasarkan hasil analisis diperoleh bahwa secara keseluruhan, masing - masing item soal yang ada di ketiga instrument tersebut dinyatakan valid berdasarkan perbandingan perolehan nlai $r$ hitung pada masing - masing item soal yang nilainya lebih besar dari nilai $\mathrm{r}$ tabel pada taraf signifikansi 5\%. Berdasarkan hasil analisis yang disajikan dalam tabel $1-3$, maka dapat dikatakan bahwa instrument yang digunakan dalam penelitian valid dan dapat digunakan untuk penelitian lebih lanjut. 


\section{b. Uji Reliabilitas Data}

Uji Reliabilitas merupakan suatu uji yang dilakukan untuk mengukur kehandalan instrument yang digunakan dalam penelitian. Uji ini dilakukan dengan menggunakan perbandingan nilai $\mathrm{r}$ tabel $(0.374)$ dengan nilai konsistensi teknik Cronbach Alpha. Instrument penelitian akan dinyatakan Reliable (handal) apabila nilai Cronbach Alpha lebih besar dari nilai $r$ tabel. Adapun hasil uji reliabilitas data disajikan dalam tabel berikut :

Tabel 4. Uji Relliabilitas Instrument Supervisi Pengawas

Reliability Statistics

\begin{tabular}{llll}
\hline \multicolumn{2}{c}{ Cronbach's Alpha } & N of Items & \\
\hline & .704 & 10 \\
\hline Sumber : Data Primer Diolah & &
\end{tabular}

Tabel 5. Uji Relliabilitas Instrument Supervisi Kepala Sekolah Reliability Statistics

\begin{tabular}{llll}
\hline Cronbach's Alpha & N of Items & 10 \\
\hline & .686 & & 10 \\
\hline
\end{tabular}

Sumber : Data Primer Diolah

Tabel 6. Uji Relliabilitas Instrument Kinerja

Reliability Statistics

\begin{tabular}{llll}
\hline Cronbach's Alpha & N of Items & 10 \\
\hline
\end{tabular}

Sumber : Data Primer Diolah

Hasil analisis data yang ditampilkan dalam tabel 4-6 merupakan hasil analisis uji reliabilitas yang dilakukan terhadap masing masing instrument yang akan digunakan dalam penelitian. Berdasarkan hasil analisis diperoleh bahwa secara keseluruhan, masing - masing item soal yang ada di ketiga instrument tersebut dinyatakan Reliable (handal) berdasarkan perbandingan perolehan nilai Cronbach's Alpha pada masing - masing item soal yang nilainya lebih besar dari nilai $\mathrm{r}$ tabel pada taraf signifikansi 5\%. Berdasarkan hasil analisis yang disajikan dalam tabel $4-6$, maka dapat dikatakan bahwa instrument yang digunakan dalam penelitian Reliable dan dapat digunakan untuk penelitian lebih lanjut.

\section{c. Uji Koefisien Korelasi}

Uji koefisien korelasi merupakan uji yang dilakukan untuk melihat pengaruh dari masing - masing variabel bebas terhadap variabel terikat. Hasil analisis disajikan dalam tabel berikut :

Tabel 7. Koefisien Korelasi Secara Simultan Model Summary

\begin{tabular}{ccccc}
\hline $\begin{array}{c}\text { Mode } \\
1\end{array}$ & R & R Square & $\begin{array}{c}\text { Adjusted R } \\
\text { Square }\end{array}$ & Std. Error of the Estimate \\
\hline 1 & $.772^{\mathrm{a}}$ & .597 & .567 & 3.03962 \\
\hline
\end{tabular}

a. Predictors: (Constant), Kepsek, pengwas Sumber : Data Primer Diolah

Analisis korelasi secara simultan digunakan untuk mengetahui hubungan antara dua variabel atau lebih. Nilai korelasi (r) ada dua arah, nilai positif menunjukkan hubungan searah (X naik maka Y naik) dan nilai negatif menunjukkan hubungan terbalik (X naik maka Y turun). Berdasarkan tabel 7, nilai koefisien korelasi variabel supervisi pengawas serta supervisi kepala sekolah (secara simultan) terhadap variabel kinerja adalah 0.772 yang mengindikasikan bahwa variabel supervisi pengawas dan supervisi kepala sekolah memiliki hubungan terhadap kinerja guru. Dan jika merujuk pada teori Sugiyono (2007) maka dapat dikatakan bahwa variabel supervisi pengawas dan supervisi kepala sekolah memiliki hubungan yang kuat dengan variabel kinerja. Dan berdasarkan tabel 7 dapat dilihat koefisien determinasi $\left(\mathrm{R}^{2}\right)$ sebesar 0,597 yang menunjukkan bahwa 59,7\% kinerja dipengaruhi oleh supervisi pengawas dan supervisi kepala sekolah sedangkan sisanya dipengaruhi oleh faktor lain. 
Tabel 8. Koefisien Korelasi Secara Parsial

Model Summary

\begin{tabular}{lccccc}
\hline $\begin{array}{l}\text { Mode } \\
1\end{array}$ & R & R Square & $\begin{array}{l}\text { Adjusted R } \\
\text { Square }\end{array}$ & Std. Error of the Estimate \\
\hline 1 & $.772^{\mathrm{a}}$ & .596 & .581 & & 2.98791 \\
\hline a. Predictors: (Constant) pengwas & & &
\end{tabular}

a. Predictors: (Constant), pengwas

Model Summary

\begin{tabular}{llrcrl}
\hline $\begin{array}{l}\text { Mode } \\
1\end{array}$ & R & R Square & $\begin{array}{c}\text { Adjusted R } \\
\text { Square }\end{array}$ & Std. Error of the Estimate & \\
\hline 1 & $.607^{\mathrm{a}}$ & .369 & .346 & & 3.73351 \\
\hline
\end{tabular}

a. Predictors: (Constant), Kepsek

Sumber : Data Primer Diolah

Tabel 8 menunjukkan hubungan antar masing masing variabel terhadap kinerja. Berdasarkan tabel dapat dilihat bahwa variabel supervisi pengawas memiliki hubungan dengan variabel kinerja dalam kategori yang kuat dengan koefisien determinasi 0,596 yang artinya $59,6 \%$ kinerja dipengaruhi oleh supervisi pengawas. Tabel 8 juga menunjukkan hubungan antara variabel supervisi kepala sekolah dengan kinerja berada dalam kategori kuat dengan koefisien determinasi 0,369 yang artinya 36,9\% kinerja dipengaruhi oleh supervisi kepala sekolah.

Tabel 9. Analisi Variansi

ANOVA ${ }^{b}$

\begin{tabular}{llrrrrr}
\hline Model & & \multicolumn{1}{c}{$\begin{array}{c}\text { Sum of } \\
\text { Squares }\end{array}$} & df & Mean Square & F & Sig. \\
\hline 1 & Regression & 368.839 & 2 & 184.419 & 19.960 & $.000^{\text {a }}$ \\
& Residual & 249.461 & 27 & 9.239 & & \\
& Total & 618.300 & 29 & & & \\
\hline
\end{tabular}

a. Predictors: (Constant), Kepsek, pengwas

b. Dependent Variable: Kinerja

Sumber : Data Primer Diolah

Tabel 9 menunjukkan hasil analisis yang dilakukan untuk menentukan koefisien signifikansi dan asumsi linearitas yan gharus dipenuhi dalam melakukan analisis regresi. Berdasarkan tabel 9 diperoleh nilai siginifikansi sebesar $0.000^{\mathrm{a}}$ yang jauh dibawah nilai kriteria signifikansi sebesar 0.05. dengan demikian, berdasarkan tabel 9 dapat dinyatakan bahwa data yang digunakan dalam penelitian signifikan dan memenuhi asumsi linearitas sehingga dapat digunakan dalam pengambilan keputusan (uji hipotesis).

Tabel 10. Uji Hipotesis Parsial

\begin{tabular}{|c|c|c|c|c|c|c|}
\hline \multicolumn{7}{|c|}{ Coefficients $^{\mathrm{a}}$} \\
\hline \multirow[t]{2}{*}{ Model } & & Unstandardiz & Coefficients & \multirow{2}{*}{$\begin{array}{c}\text { Standardized } \\
\text { Coefficients } \\
\text { Beta } \\
\end{array}$} & \multirow[t]{2}{*}{$\mathrm{t}$} & \multirow[t]{2}{*}{ Sig. } \\
\hline & & B & Std. Error & & & \\
\hline \multirow[t]{3}{*}{1} & (Constant) & 8.113 & 5.203 & \multirow{4}{*}{$\begin{array}{l}.738 \\
.044\end{array}$} & 1.559 & .131 \\
\hline & pengwas & .728 & .186 & & 3.904 & .001 \\
\hline & Kepsek & .046 & .196 & & .235 & .816 \\
\hline a. Dep & dent Varial & inerja & & & & \\
\hline
\end{tabular}

Sumber : Data Primer Diolah

Tabel 10 menyajikan hasil analisis yang dilakukan untuk menguji hipotesi 1 dan 2 yang telah dirumuskan terdahulu. Uji hipotesis dala penelitian ini dilakukan dengan melakukan perbandingan antara nila signifikansi tabel dengan kriteria signifikansi sebesar 0,05. Hipotesis akan diterima apabila nilai signifikansi lebih kecil dari 0,001. Dan berdasarkan tabel 10 diketahui nilai signifikansi untuk variabel supervisi pengawas lebih kecil dari $0,05(0,001<0,05)$ dengan demikian hipotesis diterima yang artinya supervisi pengawas berpengaruh positif dan signifikan terhadap kinerja guru. Nilai signifikansi pada variabel supervisi kepala sekolah berdasarkan tabel 10 adalah lebih 
besar dari $0,05(0,816>0,05)$ yang menjadi dasar untuk menolak hipotesis penelitian. Dengan demikian, supervisi kepala sekolah tidak berpengaruh positif dan signifikan terhadap kinerja guru.

Tabel 11. Uji Hipotesis Simultan

\begin{tabular}{|c|c|c|c|c|c|c|}
\hline \multicolumn{7}{|c|}{ ANOVA ${ }^{b}$} \\
\hline Model & & $\begin{array}{c}\text { Sum of } \\
\text { Squares }\end{array}$ & df & Mean Square & $\mathrm{F}$ & Sig. \\
\hline \multirow[t]{3}{*}{1} & Regression & 368.839 & 2 & 184.419 & 19.960 & $.000^{\mathrm{a}}$ \\
\hline & Residual & 249.461 & 27 & 9.239 & & \\
\hline & Total & 618.300 & 29 & & & \\
\hline
\end{tabular}

a. Predictors: (Constant), Kepsek, pengwas

b. Dependent Variable: Kinerja

Sumber : Data Primer Diolah

Tabel 11 merupakan tabel yang menyajikan data hasil analisis yang dilakukan untuk menguji hipotesis secara simultan. Kriteria penerimaan hipotesis pada uji ini adalah dengan membandingkan nilai signifikansi tabel dan nilai kriteria signifikansi $(0,05)$. Berdasarkan tabel 11 diketahui bahwa nilai signifikansi pada tabel lebih kecil dari $0,05(0,000<0,05)$ yang menjadi dasar untuk menerima hipotesis penelitian. Dengan demikian, dapat dikatakan bahwa Supervisi pengawas dan kepala sekolah secara simultan berpengaruh positif dan signifikan terhadap kinerja guru.

\section{d. Pembahasan}

Supervisi merupakan suatu upaya yang dapat dilakukan dalam rangka meningkatkan kinerja guru. Dalam hal ini, pelaksanaan supervisi yang berkesinambungan mampu menjaga kualitas kerja guru sehingga mampu mencapai hasil yang maksimal. Analisis data yang dilakukan dalam penelitian menunjukkan bahwa supervisi yang dilakukan oleh pengawas serta supervisi yang dilakukan oleh kepala sekolah secara simultan mampu meningkatkan kinerja guru. Kesimpulan tersebut diambil berdasarkan hasil uji hipotesis yang yang menyatakan bahwa tidak cukup bukti untuk menolak hipotesis. Persamaan regresi yang terbentuk dalam penelitian adalah $Y=8,113+0,782 X_{1}+0,46 X_{2}+e_{t}$.

berdasarkan persamaan dapat dilihat bahwa variabel supervisi pengawas memiliki pengaruh yang lebih dominan jika dibangingkan dengan supervisi yang dilakukan oleh kepala sekolah. Hal ini ditunjang oleh hasil uji hipotesis secara parsial yang menyatakan bahwa terdapat pengaruh yang positif dan signifikan antara supervisi pengawas terhadap kinerja guru, sedangkan supervisi kepala sekolah tidak berpengaruh secara positif dan signifikan terhadap kinerja guru.

Berdasarkan hasil uji hipotesis yang telah dilakukan, dapat disimpulkan bahwa kegiatan supervisi pengawas merupakan suatu upaya yang baik dalam rangka meningkatkan kinerja guru. Kegiatan supervisi yang dilakukan oleh pengawas akan berjalan dengan maksimal dengan adanya bantuan supervisi yang juga dilakukan oleh kepala sekolah. Dari analisis data juga diperoleh fakta bahwa supervisi yang hanya dilakukan oleh kepala sekolah belum mampu meningkatkan kinerja guru secara keseluruhan. Hal ini dapat disebabkan oleh kurangnya dorongan motivasi para guru jika tidak adanya pengawasan (supevisi) yang dilakukan oleh pengawas dan hanya dilakukan oleh kepala sekolah. Karennya dapat disimpulkan bahwa pengawas merupakan instrument penting dalam upaya peningkatan kinerja.

\section{KESIMPULAN \& SARAN}

Berdasarkan latar belakang serta hasil analisis data yang telah dilakukan, dapat disimpulkan beberapa hal yang diantaranya adalah :

1. Supervisi pengawas berpengaruh positif dan signifikan terhadap kinerja guru di Madrasah Ibtidaiyah Kecamatan Sukau Lampung Barat.

2. Supervisi kepala sekolah tidak berpengaruh positif dan signifikan terhadap kinerja guru di Madrasah Ibtidaiyah Kecamatan Sukau Lampung Barat.

3. Supervisi pengawas dan kepala sekolah secara bersama - sama berpengaruh positif dan signifikan terhadap kinerja guru di Madrasah Ibtidaiyah Kecamatan Sukau Lampung Barat. 
Hasil analisis data menunjukkan bahwa supervisi pengawas mampu memberikan dampak positif terhadap peningkatan kinerja guru Madrasah Ibtidaiyah Kecamatan Sukau Lampung Barat. Akan tetapi, supervisi kepala sekolahbelum mampu memberikan dampak terhadap kinerja guru. Karenanya, pada masa mendatang dirasa perlu adanya sebuah penelitian yang mengkaji faktor - faktor apa saja yang mampu meningkatkan kinerja guru khususunya bagi guru di Madrasah Ibtidaiyah Kecamatan Sukau Lampung Barat.

\section{DAFTAR PUSTAKA}

Arikunto, Suharsimi. 1989. Prosedur Penelitian : Suatu Pendekatan Praktik. Jakarta : Bumi Aksara

Brodjosejati, S. 2012. Pengaruh Supervisi Kunjungan Kelas Oleh Kepala Sekolah Dan kompensasi Terhadap Kinerja Guru Sd Negeri Di Kecamatan Sukoharjo. Jakarta : Jurnal Pendidikan dan Kebudayaan, Vol 18 No 13

Depdiknas, 2004.Standar Kompetensi Guru Sekolah Menengah Pertama. Jakarta : Depdiknas

Mantja, W. 2002. Manajemen Pendidikan dan Supervisi Pengajaran. Malang : Wineka Media

Mulyasa, E. 2007. Menjadi Kepala Sekolah Profesional. Bandung: Remaja Rosdakarya

Mustofa, R. Dwi, Dkk. 2017. Peningkatan Kinerja Guru Melalui Supervisi Pengawas Satuan Pendidikan Dan Kepemimpinan Kepala Sekolah (Studi Kasus Pada Sma Ma'arif $\mathrm{Nu} 5$ Purbolinggo Kabupaten Lampung Timur). Jurnal Manajemen Pendidikan Islam Al-Idarah, Vol 2 No 1

Natawidjaja, R. 1994. Profesionalisasi Guru. Makalah pada Seminar Pendidikan Profesional Tenaga Kependidikan. Bandung : FPS

Nawawi, H. 1981. Administrasi Pendidikan. Jakarta: Gunung Agung

-----------. 1997. Manajemen Sumber Daya Manusia untuk Bisnis Kompetitif.

Priyatno, D. 2008. Mandiri Belajar SPSS-Bagi Mahasiswa dan Umum. Yogyakarta : MediaKom

Purwanto, M. Ngalim, 2005. Administrasi dan Supervisi Pendidikan. Bandung : Remaja Rosdakarya

Sagala, S. 2010. Supervisi Pembelajaran. Bandung: Alfabeta
Simamora, H. 2006. Manajemen sumber daya manusia. Yogyakarta : Bagian Penerbitan Sekolah Tinggi Ilmu Ekonomi YKPN

Sudjana, Nana, dkk. 2006. Standar Mutu Pengawas. Jakarta: Dirjen PMPTK DirektoratTenaga Kependidikan Depdiknas.

Sugiyono. 2007. Statistika Untuk Penelitian. Bandung: ALFABETA

Sumarni, S. Dkk. 2017. Pengaruh Supervisi Akademik Pengawas Sekolah, Kepemimpinan Kepala Sekolah Dan Lingkungan Kerja Terhadap Kinerja Guru Smk Negeri Se-Kecamatan Tamalate Kota Makassar. Makasar : Jurnal Mirai Management, Vol 2 No 1 2017

Supriono, E. 2014. Pengaruh Supervisi Kepala Sekolah Terhadap Kinerja Guru Sd Sekecamatan Sewon Bantul Yogyakarta. Skripsi. Yogyakarta : UNY Yogyakarta: UGM Press

Yunita, 2017. Supervisi Kepala Sekolah Dalam Pembinaan Kinerja Guru Di Man Kota Bakti Pidie. Skripsi. Aceh : UIN ArRaniry 